Original Article

\title{
UPTAKE PATTERN OF HIV COUNSELING AND TESTING SERVICES: A 4-YEAR REVIEW IN PLATEAU STATE, NIGERIA
}

\author{
Magaji F.A*, Ocheke A.N, Pam V.C, Afolaramin T. ${ }^{1}$, Musa J., Sagay A.S, Zoakah A.I. ${ }^{1}$

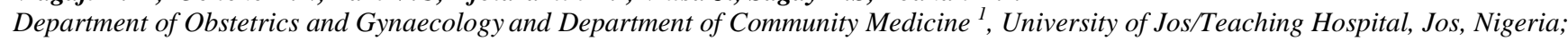

*Corresponding Author: Dr Magaji F.A, Department of Obstetrics and Gynaecology,University of Jos/Teaching Hospital, Jos, Nigeria. Email: ikoseng@yahoo.com

Received date: May $23^{\text {th }} 2018$, Accepted date: June $18^{\text {th }}$ 2018. Published date: June $30^{\text {th }} 2018$.

\section{Abstract}

Plateau state is one of the HIV high-burden states in Nigeria with few people knowing their HIV status as a result of challenges with access to HIV Counseling and Testing (HCT) services. This study was aimed at determining the HCT uptake among the general population as well as the pattern by age and sex in Plateau state. The study was a 4-year descriptive analysis of HCT services in the general population of Plateau state, Nigeria based on data generated between January 2012 and December 2015. The data on HCT services were managed through the electronic Nigerian National HIV/AIDS Response Information Management System (eNNRIMS) which was webbased software. The data was disaggregated by year, age and sex in the software and analysis was done using excel to obtained the proportions and trend of HCT uptake in the general population and by year, age and sex. Out of a total of 495,718 tested for HIV, 400,699 people received their test results giving an $80.8 \%$ HCT uptake in Plateau state. The highest (99.7\%) HCT uptake was in 2014 and the least (67.7\%) was in 2012 . The age group 25 - 49 years accounted for nearly two-thirds of HCT uptake. The female population had higher percentages of between $7.2 \%$ and $17.6 \%$ HCT uptake across the years compared to their male counterparts. The HCT uptake was relatively high, and it was even higher among the female population compared to the HCT uptake among male population in Plateau state Nigeria.

Keywords: Counseling, HIV, Plateau State, Testing, Uptake,

\section{Introduction}

Every year, it is estimated that 2.3 million new HIV infections occurred globally with sub-Saharan Africa contributing $80 \% .^{1,2,3}$ In a World Health Organization (WHO) report on universal access in 2008, on the average, as few as $10.3 \%$ of men and $10.9 \%$ of women in the general population had ever been tested for HIV and received their test results. Also, a global median of $20 \%$ of people living with HIV actually knew their HIV status. ${ }^{4}$ HIV Counseling and Testing refers to the intervention that gives individuals or couples an opportunity to confidentially discuss the risk of HIV infection and be assisted to learn HIV status for the purpose of prevention, care and treatment. ${ }^{5}$

Although access and coverage vary greatly by country, survey data from 2008-20012 in most sub-
Saharan African countries indicated that less than 1 in 3 adolescent girls aged 15-19 years reported having ever tested for HIV and received the results. ${ }^{5}$ In the Eastern and Southern Africa, 29\% of adolescent girls' age 15-19 years reported having ever had an HIV test and have received the results, which was higher than adolescent boys (20\%). This was attributed to early pregnancies that led to care at maternal health services and HIV testing. ${ }^{6}$ In 2012, the number of men and women age 15-49 years who received HIV testing and counseling in the previous 12 months and who knew their results (excluding pregnant women) in Nigeria was $2,628,108 .^{7}$ The 2012 National HIV/AIDS and Reproductive Health Survey (NARHS) reported that the HIV Counseling and Testing (HCT) uptake was $62.5 \%$ of 4547 females and $68.3 \%$ of 3657 males who 
were tested and received results. The age 40-49 years and 50-64 years had $68.7 \%$ and $71.6 \%$ respectively, and only $55.1 \%$ of age $15-19$ years were tested and received their results. ${ }^{8}$ In 2013 NDHS report, out of 38,948 women surveyed in Nigeria, one in four women $(25.3 \%)$ had tested for HIV and received the result of the last test, and the corresponding proportion was $20.4 \%$ of 17,359 men surveyed. Also, 7 in 10 women $(70 \%)$ and $78.1 \%$ of men had never tested for HIV. Among women and men tested for HIV in the previous 12 months, $10.1 \%$ of the women and $9.9 \%$ of men received their test results, an improvement from $7 \%$ each in the 2008 NDHS report. ${ }^{9}$

Studies on uptake pattern of HCT services are used in developing policies to achieve global development agenda including UNAIDS ambitious 90-90-90 targets by $2030-90 \%$ of HIV-positive people in the general population knowing their status, $90 \%$ of HIV-positive people who are aware of their status on ART, and $90 \%$ of people on ART virally suppressed. ${ }^{10}$ There are limited studies on the pattern of HCT uptake in Plateau state; the study was aimed at reviewing the HCT services uptake from 2012 to 2015 and how it was affected by age and gender in Plateau state, Nigeria.

\section{Materials and Methods}

The study was conducted in Plateau State, NorthCentral zone of Nigeria located between latitude 80 ${ }^{0} 24^{\prime} \mathrm{N}$ and longitude $80^{\circ} 32^{\prime}$ and $100^{\circ} 38^{\prime}$ East. The state is bounded in the North-East by Bauchi state, North-West by Kaduna state, South-East by Taraba state and to the South-West by Nasarawa state. It has an Area of 26,899 square kilometers and administratively divided into 17 Local Government Areas (LGAs).The population of the state from 2006 census was 1,598, 998 males and 1,607,533 females, and a total of $3,206,531$. With an annual growth rate of about $2.7 \%$, the projected population in the state was approximately 4,075,391 people as of the year 2015.

As of 2015, the HIV prevalence in the state was 5.9\% indicating a reduction from $7.7 \%$ in 2010 which made Plateau state the $6^{\text {th }}$ in the 12 states plus FCT with the highest burden $(70 \%)$ of HIV/AIDS in Nigeria. Plateau state had 147,221 PLHIV as of 2011 with Implementing Partners (IP) including AIDS Prevention Initiative in Nigeria (APIN), Institute of Human Virology in Nigeria (IHVN), AIDS RELIEF and Family Health International (FHI 360) among others who supported the state Government in the HIV/AIDS response. Following rationalization of US Government supported IPs in 2012, APIN became the Lead IP in Plateau state and other IPs were assigned to lead other states. APIN supported Plateau state to scale up HIV/AIDS services in over 48 health centers including Faith-Based health facilities, some key private health facilities and Local NGOs working in hard-to-reach communities.

The study was a 4-year descriptive analysis of HCT services in the general population of Plateau state, Nigeria based on data generated between January 2012 and December 2015. Ethical approval was obtained from JUTH ethical review committee and the authorization to use the state data was obtained from Plateau State Ministry of Health. The data were collected on a continuous basis from all health service delivery points and mobile or out-reaches in all the 17 Local Government Areas of Plateau state and with the targeted population being females and males of all ages (excluding pregnant women). The review was based on the diagnosis of HIV infections delivered by physicians and or laboratories which were entered in to the newly instituted monitoring and evaluation system in the state. In addition, the harmonization of the monitoring and evaluation system for data collection and reporting tools and template had been strengthened in the state.

The data on HCT services were managed through the electronic Nigerian National HIV/AIDS Response Information Management System (eNNRIMS) which was web-based software. The data were captured into the HCT Tools (Registers) and referred to as source document and the tools included; HCT Register, Client intake form, Request and Result form, HCT worksheet and HCT monthly summary form with all the tools in hardcopies domiciled at the service delivery point (SDP).The eNNRIMS was centrally coordinated with hierarchy of privileges from the SDP, through the Local Government level, the state and the national levels. The infrastructure and capacity of Operators of the eNNRIMS were strengthened and with internet access to allow data entry and validation. Data from the source registers were entered into the eNNRIMS at the facility level with first verification at the LGA. The second and third verifications were done at the state and national levels respectively. At the state level, monthly Monitoring\& Evaluation ( $M$ \& E) meetings were held with participation of key $M$ \& E stakeholders from IPs, State Ministry of Health, Plateau State Agency 
for the Control of AIDS (PLACA) and Local Government officers. The monthly meetings were aimed at ensuring completeness, adequacy and accuracy of the data. Validation meetings were held quarterly to review source documents for HCT across SDPs against the electronic data platform for correctness and appropriateness. The same validations were held on semester bases at the national level with M \& E officers from IPs, NASCP, NACA and state officers to finalize and confirm the correctness of the data across states including Plateau state. Data was retrieved from the data base manually for analysis. The extracted data were analyzed using excel. Results were presented by cross-tabulations for year, Age, and
Sex. Also, the result was presented in line graphs for years, and Bar charts to represent HCT uptake in Plateau state.

\section{Result}

The results showed that within the study period, a total of 495,718 people were tested for HIV. About 30,450 people tested positive for HIV, and 400,699 people received their test results. There was a steady increase in the number of people tested for HIV from 45,366 people in 2012 to 280,240 people in 2015 . The age group 25 years to 49 years accounted for nearly two-thirds of the HCT uptake in the study period (Table 1, Figure 1).

Table 1: The HCT Uptake by age and sex between $2012-2015$

\begin{tabular}{|c|c|c|c|c|c|c|c|c|}
\hline & \multicolumn{4}{|c|}{ Male } & \multicolumn{4}{|c|}{ Female } \\
\hline & 2012 & 2013 & 2014 & 2015 & 2012 & 2013 & 2014 & 2015 \\
\hline & $\mathrm{n}(\%)$ & $\mathrm{n}(\%)$ & $\mathrm{n}(\%)$ & $\mathrm{n}(\%)$ & $\mathrm{n}(\%)$ & $\mathrm{n}(\%)$ & $\mathrm{n}(\%)$ & $\mathrm{n}(\%)$ \\
\hline \multicolumn{9}{|c|}{ Age (years) } \\
\hline $0-14$ & $1773(9.5)$ & 2837 (11.8) & $7846(15.1)$ & 20614 (15.9) & $1705(6.4)$ & $2739(9.1) \quad 7$ & 7606 (11.9) & $19806(13.2)$ \\
\hline $15-19$ & $311(1.7)$ & $637(2.7)$ & $1357(2.6)$ & 1918 (1.5) & 459 (1.7) & $1315(4.3)$ & $1689(2.6)$ & $3706(2.5)$ \\
\hline $20-24$ & 2108 (11.3) & $3183(13.2)$ & $3365(6.5)$ & $6643(5.1)$ & $7217(27.1)$ & $5330(17.6)$ & $5106(8.0)$ & $9478(6.3)$ \\
\hline $25-49$ & $13974(74.8)$ & $15402(64.1)$ & $38310(73.9)$ & $94823(72.9)$ & $16893(633)$ & $18829(62.2)$ & ) $48437(75.7)$ & 115198 (76.7) \\
\hline$\geq 50$ & $521(2.8)$ & $1964(8.2)$ & 971 (1.9) & $6094(4.6)$ & 405 (1.5) & $2058(6.8))$ & $1111(1.7)$ & $1960(1.3)$ \\
\hline Total & $18687(100)$ & 24043 (100) & $51849(100)$ & $130092(100)$ & $26679(100)$ & $30271(100)$ & $63949(100)$ & $150148(100)$ \\
\hline
\end{tabular}

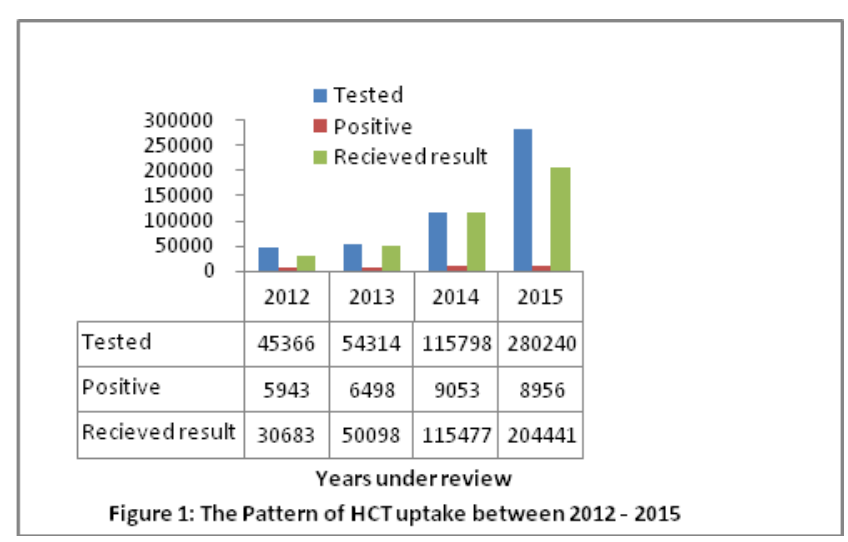

J. Biomed. Res. Clin. Pract., Vol.1. No.2, 2018.

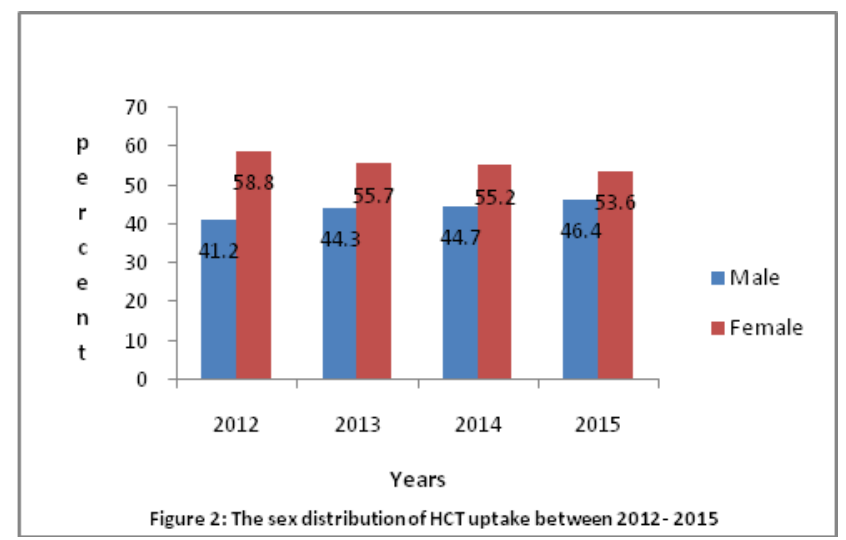

In all the study years, there was more HCT uptake among females compared to the males with the widest difference of $17.6 \%$ in 2012 which was narrowed to $7.2 \%$ in 2015 (Figure 2). 


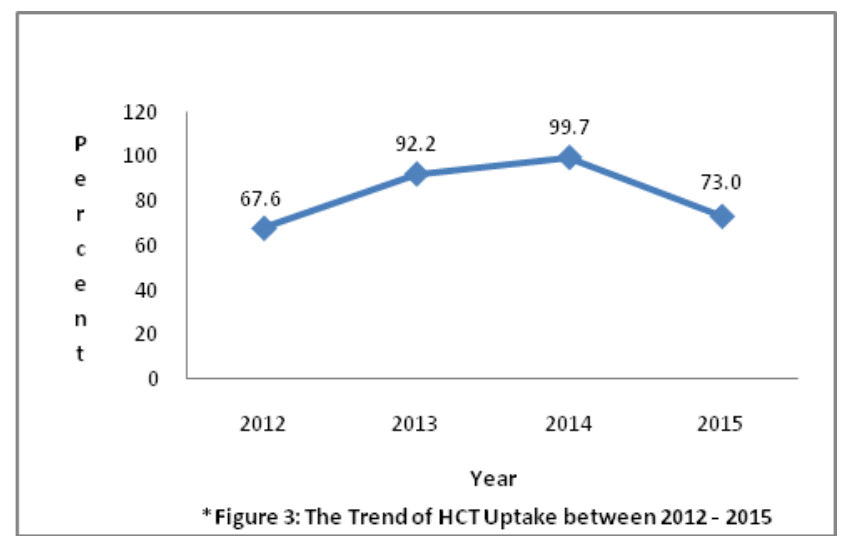

The mean HCT uptake was $80.8 \%$ in Plateau state in the study period and the trend showed that HCT uptake was highest (99.7\%) in 2014 and lowest (67.6\%) in 2012 (Figure 3).

\section{Discussion}

Our study showed that on the average, the HCT uptake in Plateau state was $80.8 \%$ of the total number of 495,718 people tested for HIV. The least HCT uptake of $67.6 \%$ was reported in 2012 and $99.7 \%$ reported in 2015 . The study showed that there was a steady increase in HCT services from 45,366 in 2012 to 280,240 in 2015 . Similar pattern was observed in Nigeria, as a whole, total number of persons who were counseled, tested and received results stood at $3,371,220$ at the end of $2008 ; 2,287,805$ by the end of 2010 and in 2011 , it was on $2,056,578 .{ }^{12}$ Failure to test for HIV means that people can easily be infected or infect others compromising the control and prevention of HIV/AIDS.

As of 2015 , only $12.1 \%$ of the projected population of Plateau state had been tested for HIV with about $87.9 \%$ yet to be tested. This gap has serious public health implications on the efforts to prevent new HIV transmissions. Uptake of HCT is low globally, UNAIDS report of 2006 indicated that only $10 \%$ of infected individuals worldwide are aware of their HIV status, and in Nigeria, over $60 \%$ of HIV positive people still don't know their HIV status. ${ }^{4}$ The first step towards HIV prevention is knowing the HIV status of the population for appropriate deployment of preventive tools for HIV control. However, this will form the baseline for the target of $90 \%$ of the population tested for HIV and received results in the Sustainable Development Goal (SDG) 3by 2030 in Plateau state.

Also, the age group 15 years to 24 years accounted for less than $30 \%$ of the total HCT uptake in Plateau state. Youths are particularly underrepresented among those accessing HCT services. HCT uptake among the students of tertiary institutions in Nigeria ranges from $8.3 \%$ to less than $30 \% .^{13-15}$ Since the youths are not accessing HCT, HIV infections are likely to go unrecognized and untreated and opportunities for prevention and control will not be utilized. Young people offer the greatest hope for changing the course of the HIV/AIDS epidemic and key to the success of the $90 \%$ attainment of the population knowing their HIV status and SDG 3 by 2030; therefore, they must be assisted to see the need for HCT uptake.

The HCT uptake was also affected by variation among sex groups with more females having higher HCT uptake in all the years 2012 to 2015 compared to males. Similar findings are reported in studies at the national level in Nigeria and other countries in subSaharan Africa. ${ }^{5}{ }^{6}$ This is however not surprising considering the differences in health seeking behavior between male and female populations in our settings the female population has more tendencies of accessing health care services including HCT compared to the male population. It means that, reproductive health services should target more males in order to close the gaps existing in HCT uptake in the state in line with the global consensus on HIV Counseling and Testing stating that more people urgently need to know their HIV status so that they can benefit from prevention, care and treatment.

The application of the reported findings would be limited considering the fact that beside the potential for incorrect data entry by the data officers, the use of secondary data gave us little opportunity to include other variables in the analysis especially that the secondary data was not disaggregated into individual subjects for multivariate logistic regression analysis of determinants for HCT uptake in the general population. However, these findings could be use at the policy level to strengthen strategies towards achieving $90 \%$ of HCT uptake in Plateau state.

\section{Conclusion}

The HCT uptake was relatively high and even higher uptake was recorded among the female population compared to the HCT uptake among the male population. Scaling up of HCT services to improve access for the younger age groups especially the male population will increase HCT coverage in Plateau state Nigeria. 


\section{Conflict of Interests}

The authors declare no conflict of interests.

\section{Acknowledgement}

Research reported in this publication was supported by the Fogarty International Centre (FIC); Office of the Director (OD/NIH); National Institutes of Neurological Disorders and Stroke (NINDS/NIH); and the National Institute of Nursing Research (NINR/NIH) of the National Institutes of Health under award number D43TW010130. The content is solely the responsibility of the authors and does not necessarily represent the views of the National Institutes of Health. The authors also thank the Hon. Commissioner for Health Plateau state, the Coordinator and staff of the state HIV/AIDS and STI Control programme, the staff of Plateau state HIV/AIDS Control Agency, Civil Society Networks/NGOs on HIV/AIDS, and Implementing Partners for providing the HIV services and generating the data used in this study.

\section{References}

1. Iwuji CC. Evaluation of the impact of immediate versus WHO recommendations-guided antiretroviral therapy initiation on HIV incidence: the ANRS 12249 TasP (Treatment as Prevention) trial in Hlabisa sub-district, KwaZulu-Natal, South Africa: Study protocol for a cluster randomized control trial. 2013; 14: 230.

2. UNAIDS. 2011. World AIDS day report 2011. Geneva, Switzerland. UNAIDS Available at http://www.unaids.org/en/media/unaids/contentass ets/documents/unaidspublication/2011/jc2216_wo rldaidsday_report_2011_en.pdf.

3. Kranzer K, Govindasamy D, Ford N, Johnson V, Lawn SD. Quantifying and addressing losses along the continuum of care for people living with HIV infection in sub-Saharan Africa: a systematic review. J. Inter. AIDS Soc. 2012;15: 17383.

4. Bateganya M, Abdulwadud OA, Kiene SM. Home-based HIV Voluntary Counseling and Testing (VCT) for improving uptake of HIV testing. Cochrane Database Syst Rev 2010(7): CD006493.

5. Resenberg NE, Westreich D, Barnighausen $\mathrm{T}$, et al. Assessing the effect of HIV counseling and testing on HIV acquisition among South African youth. AIDS. 2013; 27: 2765-2773.
6. United Nations Children's Fund (UNICEF). Towards an AIDS-free Generation- Children and AIDS: Sixth Stocktaking Report, 2013. New York, NY: UNICEF; 2013

7. Federal Ministry of Health. National HIV Sentinel Survey among pregnant women attending Antenatal Clinic in Nigeria 2010: Technical Report. National AIDS/STI Control Programme. Abuja, Nigeria. 34-41.

8. Federal Ministry of Health. National HIV/AIDS and Reproductive Health Survey 2012, NARHS Plus II.

9. National Population Commission (NPC) \{Nigeria\} and ICF International. Nigeria Demographic and Health Survey 2013. Abuja, Nigeria and Rockville, Maryland, USA. NPC and ICF International.

10. UNAIDS Fast-Tract: Ending the AIDS Epidemic by2013http://www.unaids.org/sites/default/files/m edia_asset/C2686_WAD2014report_en.pdf (UNAIDS 2014).

11. National Population Commission (2006). Population and Housing Census. National Population Commission, Abuja, Nigeria. 2010; (4): 304-311.

12. Nigerian National Agency for the Control of AIDS (NACA). President's Comprehensive Response Plan for HIV/AIDS in Nigeria. National Agency for the Control of AIDS. 2013.

13. Adewole DA, Lawoyin TO. Characteristics of volunteers and non-volunteers for voluntary counseling and HIV testing among unmarried male undergraduates. Africa Journal of Medical Science. 2004; 33: 165-170.

14. Ikechebelu IJ, Udigwe GO, Ikechebelu N, Imoh LC. The knowledge, attitude and practice of voluntary counseling and testing (VCT) for HIV/AIDS among undergraduates in a Polytechnic in southeast, Nigeria. Nigerian Journal of Medicine. 2006; 15(3), 245-249.

15. Ike SO, Aniebue PN. HIV/AIDS perception and sexual behavior among Nigerian University students. Nigerian Journal of Clinical Practice. 2007, 10:105-110. 